\title{
Evaluation of posterior ocular changes using enhanced depth imaging-optical coherence tomography in patients with obstructive sleep apnea syndrome
}

\author{
Avaliação das alterações oculares posteriores utilizando tomografia de coerência óptica de profundidade \\ aprimorada em pacientes com síndrome de apneia obstrutiva do sono
}

İsa Yuvaci $^{1}$, Emine Pangal ${ }^{1}$, Nurettin Bayram ${ }^{1}$, Sevgl Arik Yüksel ${ }^{2}$, Bedirhan Alabay ${ }^{1}$, Alperen Ağadayı ${ }^{1}$, Ender Sirakaya ${ }^{1}$, Ahmet Gülhan ${ }^{1}$

\begin{abstract}
Purpose: Evaluation of the nerve fiber thicknesses of the macula, choroid, and retina using the apnea-hypopnea index in individuals with obstructive sleep apnea syndrome (OSAS) without systemic components.

Methods: Prospective, controlled study. The central macular, choroidal, and retinal nerve fiber layer (RNFL) thicknesses were evaluated using enhanced depth imaging-spectral domain optical coherence tomography in individuals with OSAS. In people with severe OSAS who had received treatment, posterior ocular structures were examined over 3 months ( $4^{\text {th }}$ and $12^{\text {th }}$ weeks), and changes were evaluated. Only the right eyes of the participants were evaluated in the study. Results: A total of 72 people were involved in the study, with 18 in the control group and 19 with mild, 16 with moderate, and 19 with severe OSAS. No significant difference was found among the groups in terms of demographic measures. No significant differences were found among the groups in terms of the measures of central macular, central subfoveal choroidal (CSCT), temporal choroidal, nasa choroidal, and RNFL thicknesses. In severe OSAS cases in which treatment was administered, although subjective clinical recovery was observed, statistically sig nificant thinning was detected during the 3-month follow-up period in the CSCT general RNFL, as well as in the inferior and superior nasal quadrants, and temporal superior quadrant ( $p=0.005, p=0.009, p=0.039, p=0.003$, and $p=0.02$, respectively). Conclusion: In the group with severe OSAS, thinning in some posterior ocular tissues was observed. Although patients with severe OSAS may experience clinical recovery, we recommend that they would be followed up in terms of ocular ischemic injury.
\end{abstract}

Keywords: Sleep apnea syndromes; Macula; Choroid; Tomography, optical coherence; Nerve fibers; Retina

\section{RESUMO}

Objetivo: Avaliação de espessuras das fibras nervosas da mácula, coroide e da retina de acordo com os índices de apnéia e hipopnéia (AHI) em indivíduos com síndrome da apneia obstrutiva do sono (OSAS), sem componentes sistêmicos.

Métodos: Estudo prospectivo, controlado. As espessuras centrais maculares, da coroide e da camada de fibras nervosas da retina foram avaliadas tomografia de coerência óptica de domínio espectral de profundidade aprimorada em indivíduos com sindrome da apneia obstrutiva do sono. Em pessoas com OSAS grave a quem foi aplicado o tratamento, estruturas oculares posteriores foram examinados por três meses (4a e 12 semanas) e as alterações foram avaliadas. Apenas os olhos direitos dos participantes foram envolvidos no estudo.

Resultados: 72 pessoas foram envolvidas no estudo, 18 no grupo controle e, 19 com OSAS leve, 16 com OSAS moderada e 19 com OSAS grave. Não houve diferença significativa entre os grupos em relação às medidas demográficas. Não houve diferenças significativas estavam presentes entre os grupos em termos de medidas de espessura macular central (CMT), espessura subfoveal central da coroide (CSCT), espessura da coroide temporal (TCT), espessura da coroide nasal (NCT) e, a camada de fibras nervosas da retina (RNFL). Em casos de OSAS graves onde o tratamento foi aplicado, apesar de ter sido observada recuperação clínica subjetiva, detectou-se afinamento estatisticamente significativo durante os três meses de acompanhamento, em CSCT, RNFL geral, quadrantes nasais inferior e superior, e quadrante temporal superior $(p=0,005, p=0,009, p=0,039, p=0,003, p=0,02)$.

Conclusão: No grupo com OSAS grave, foi observado afinamento em algumas áreas posteriores dos tecidos oculares. Embora os pacientes com OSAS grave possam apresentar recuperação clínica, recomendamos que eles sejam seguidos em termos de lesão isquêmica ocular.

Descritores: Síndromes da apneia do sono; Macula; Coroide; Tomografia de coerência óptica; Fibras nervosas; Retina

\section{INTRODUCTION}

Obstructive Sleep Apnea Syndrome (OSAS), which is the complete or partial obstruction of the upper airways recurrently during sleep, is fairly common, at rates of $3 \%-7 \%$ in the population ${ }^{(1,2)}$. Resultant hypercapnia and re-oxygenation cause humoral and vascular changes by modifying several blood parameters such as lowering of $\mathrm{pH}$, increasing of nitric oxide (NO), and vasodilatation caused by hypoxia. Consequently, changes occur in the balance between vasodilatation and vasoconstriction in blood vessels. Additionally, hypercapnia causes an increase in tonus by causing systemic autonomic dysfunction. Eventually, apnea and hypopnea contribute to the development of complications such as atherosclerosis, endothelial dysfunction, vascular remodeling, and hypertension; and this condition might transform apnea and hypoapnea into a harmful stimulants for the cardiovascular system ${ }^{(3-5)}$. Continuous positive airway pressure (CPAP) is used for the treatment of OSAS ${ }^{(6)}$.

The choroidal tissue has extensive vasculature and can easily adapt to resultant systemic changes. In contrast to other posterior ocular tissues, choroidal vessels are subjected to systemic autonomic regulation ${ }^{(7)}$. Therefore, the choroid is affected by the resultant autonomic dysfunction. In addition, normally, endothelin levels are more predominant than NO in choroidal blood flow, and, there exits systemic
Funding: No specific financial support was available for this study. Disclosure of potential conflicts of interest: None of the authors have any potential conflict of interest to disclose.

Corresponding author: İsa Yuvacı. Kayseri Training and Research Hospital Eye Clinic. Hastane Str, 38010 - Kocasinan, Kayseri - Turkey - E-mail: mdisay@hotmail.com

Approved by the following research ethics committee: Erciyes University Ethics Committee (\#2014/464). 
increase in NO level in OSAS ${ }^{(8,9)}$. For these reasons, choroidal evaluation can not only show the influence of the disease on ocular tissues but can also be a useful indicator for early determination of systemic vascular injury. Main explanations for existing retinal thickness might be changes in vascular permeability that can occur due to alteration in hemodynamic parameters, such as hypoxia and hypercapnia; increase in growth factors and the extension of the process as a result of apnea and hypopne.

Hypercapnia-hypoxia that occurs at night because of the disease can cause injury in the head of the optic nerve, which is extremely sensitive to hypoxia, and ganglion cell ${ }^{(10,1)}$. Glaucoma is more commonly seen in individuals with the disease ${ }^{(10)}$. Impairment of the balance between $\mathrm{NO}$ and endothelin is one of the factors which is attributed with ganglion cell injury in patients with glaucoma. As mentioned above, the delicate balance between $\mathrm{NO}$ and endothelin is also impaired in OSAS, and this suggests that glaucoma-like injury can occur. Increases in intraocular pressure (IOP) can affect the optic nerve and make it more sensitive to glaucoma-like injury. The more glaucoma and hypoxic medium, the more ganglion cells and optic nerve are vulnerable to high rates of injury.

Spectral domain optic coherence tomography (SD-OCT) can detect low degree retinal nerve losses in these tissues during the early stages of OSAS.

The effect of OSAS on the macula, choroid, and retinal nerve fiber layer (RNFL) has not been comprehensively studied ${ }^{(12-15)}$; moreover, these studies have conflicting results. Most of these studies have assessed the choroidal and RNFL or choroidal and retinal thickness. However, in our present study, all of the retinal, choroidal, and RNFL thicknesses have been evaluated. The aim of the present study is to evaluate posterior ocular structures in patients with newly diagnosed OSAS without any systemic disease and also evaluate posterior ocular alterations before treatment and during a 3-month follow-up.

\section{METHODS}

The present study was conducted in our clinic between February 2014 and January 2015. Approval was obtained from the Erciyes University Ethics Committee for the study, which was conducted in accordance with the principles of the Helsinki Declaration. Written and verbal consent was obtained from the participants.
Inclusion criteria were $>18$ years of age, diagnosis with OSAS for the first time, no treatment received for OSAS, and no other systemic disease. Exclusion criteria were corrected visual acuity $<0.8$, a history of previous ocular surgery or intravitreal injection, presence of any ocular disease, spherical equivalent (SE) greater than +3 diopters (D), SE value lesser than -3 D, and ocular axial length $(A L)>24.99 \mathrm{~mm}$.

Following polysomnography performed in the Neurology Sleep Laboratory, patients were classified according to the frequency of apnea-hypopnea per hour of sleep (apnea-hypopnea indexes, AHI). Those with $<5 \mathrm{AHI}$ were placed in the control (C) group, those with 5-15 AHI were classified in the mild (M) OSAS group, those with 15-30 AHI were classified in the moderate (Mo) OSAS group, and those with $\geq 30 \mathrm{AHI}$ were classified in the severe (S) OSAS group ${ }^{(16)}$

All patients underwent routine ophthalmological examination, and biometric measurements were made using an IOL Master (Carl Zeiss Meditec, Dublin, CA). Later, the macula, choroid, and RNFL thicknesses were measured with SD-OCT in each patient. Those individuals who were diagnosed with severe OSAS and for whom treatment was started were re-evaluated after 4 and 12 weeks in terms of ocular examination and measurement of the posterior ocular structures. Only the right eyes of the participants were evaluated in the present study.

\section{Procedure of image acquisition}

The central macular thickness (CMT), RNFL thicknesses, and choroidal thickness (CT) measurements were obtained using the Spectralis SD-OCT (Heidelberg Engineering; wavelength: $870 \mathrm{~nm}$ ) with the enhanced depth imaging modality that has previously been described) (Figure 1)(16). All subjects were imaged by the same experienced technician. The central subfoveal choroidal thickness (CSCT), temporal choroidal thickness (TCT; $1 \mathrm{~mm}$ temporal CT from the fovea), and nasal choroidal thickness (NCT; $1 \mathrm{~mm}$ nasal CT from the fovea) were measured by two clinicians (I.Y. and E.P.) in a blinded manner, without knowledge of information of the subjects, and the mean of their measurements was used in the analysis. Measurements with a difference larger than 10\% between the clinicians were excluded from the study. The peripapillary RNFL thickness parameters were automatically calculated using the same SD-OCT device and divided into regions including nasal $(\mathrm{N})$ quadrant thickness $\left(90^{\circ}\right)$, nasal superior (Ns) quadrant thickness $\left(45^{\circ}\right)$, nasal inferior (Ni) qua-

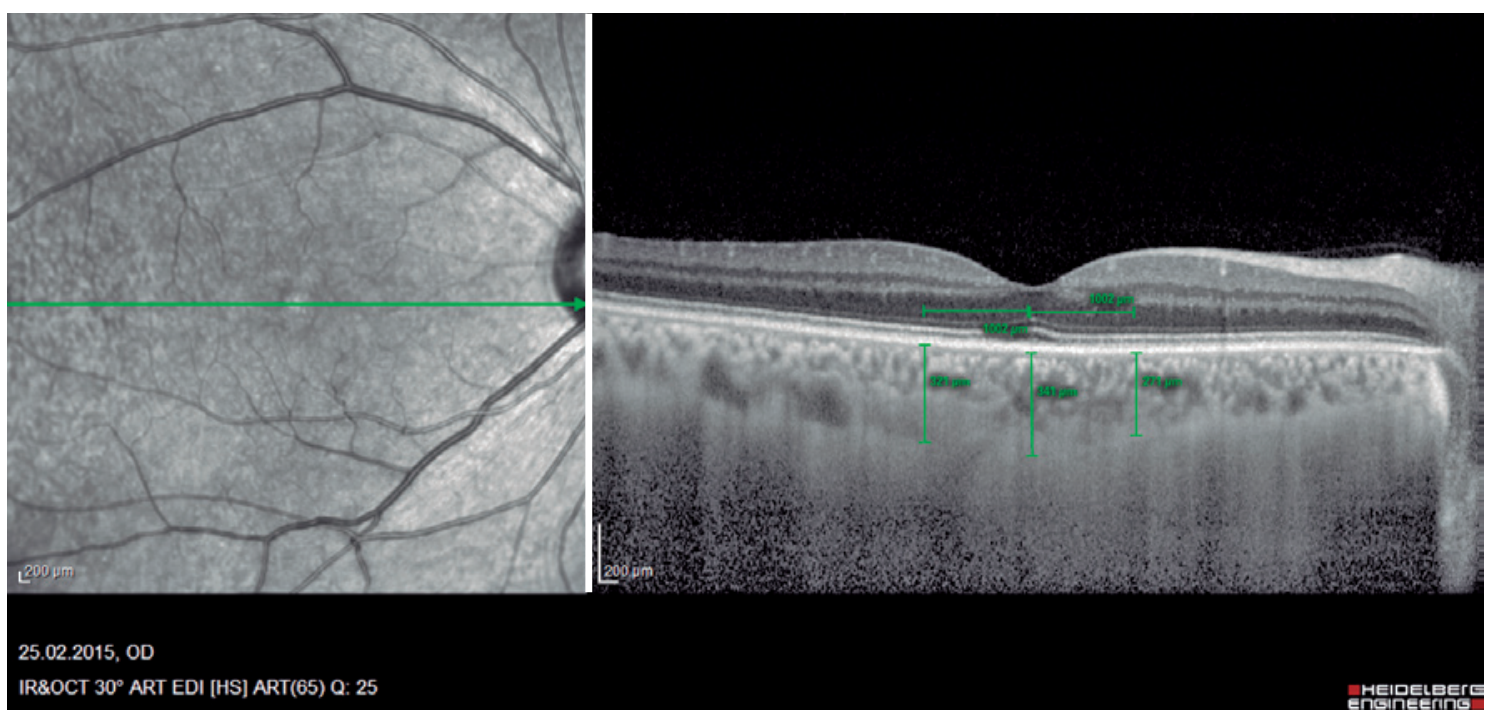

Figure 1. Example of enhanced depth imaging-optic coherence tomography measurements. Central subfoveal choroidal thickness (CSCT), temporal choroidal thickness (TCT; $1 \mathrm{~mm}$ temporal CT from the fovea), and nasal choroidal thickness (NCT; $1 \mathrm{~mm}$ nasal CT from the fovea). 
drant thickness $\left(45^{\circ}\right)$, temporal $(\mathrm{T})$ quadrant thickness $\left(90^{\circ}\right)$, temporal superior (Ts) quadrant thickness $\left(45^{\circ}\right)$, temporal inferior (Ti) quadrant thickness $\left(45^{\circ}\right)$, and mean (G) thickness $\left(360^{\circ}\right.$ ) (Figure 2). To minimize the possibility of choroidal changes attributable to diurnal choroidal fluctuations ${ }^{(17)}$, all scans were performed during the same time of the day between 11:00 a.m.-12:00 p.m.

\section{Statistical analyses}

All statistical analyses were performed using SPSS for Windows version 22.0 (IBM Corp., Armonk, NY, USA). Continuous variables were presented as the mean \pm standard deviation. Normal distribution was evaluated using the Kolmogorov-Smirnov test. Homogeneity of variances was tested using Levene's test. The one-way analysis of variance (ANOVA) test was used to analyze parametric data. When a significant result was obtained, Scheffé's test was used for post hoc comparisons. For non-parametric statistics, data were analyzed using the Kruskal-Wallis test. When a significant result was obtained, the Mann-Whitney $U$ test with Bonferroni's correction was used for post hoc comparisons. Differences between variables at specific time points of severe OSAS patients were analyzed by the repeated measures ANOVA test. A $P$ value of $<0.05$ was considered statistically significant.

\section{RESULTS}

Seventy-two patients with OSAS participated in the present study. Patients were classified according to the AHI.

The demographic and clinical data of the participants are given in detail in table 1. No statistically significant difference was observed among the groups in terms of age, AL, IOP, or SE. However, the body mass index (BMI) was significantly higher in group $S$ than in the other groups, whereas no significant difference existed among the other groups.
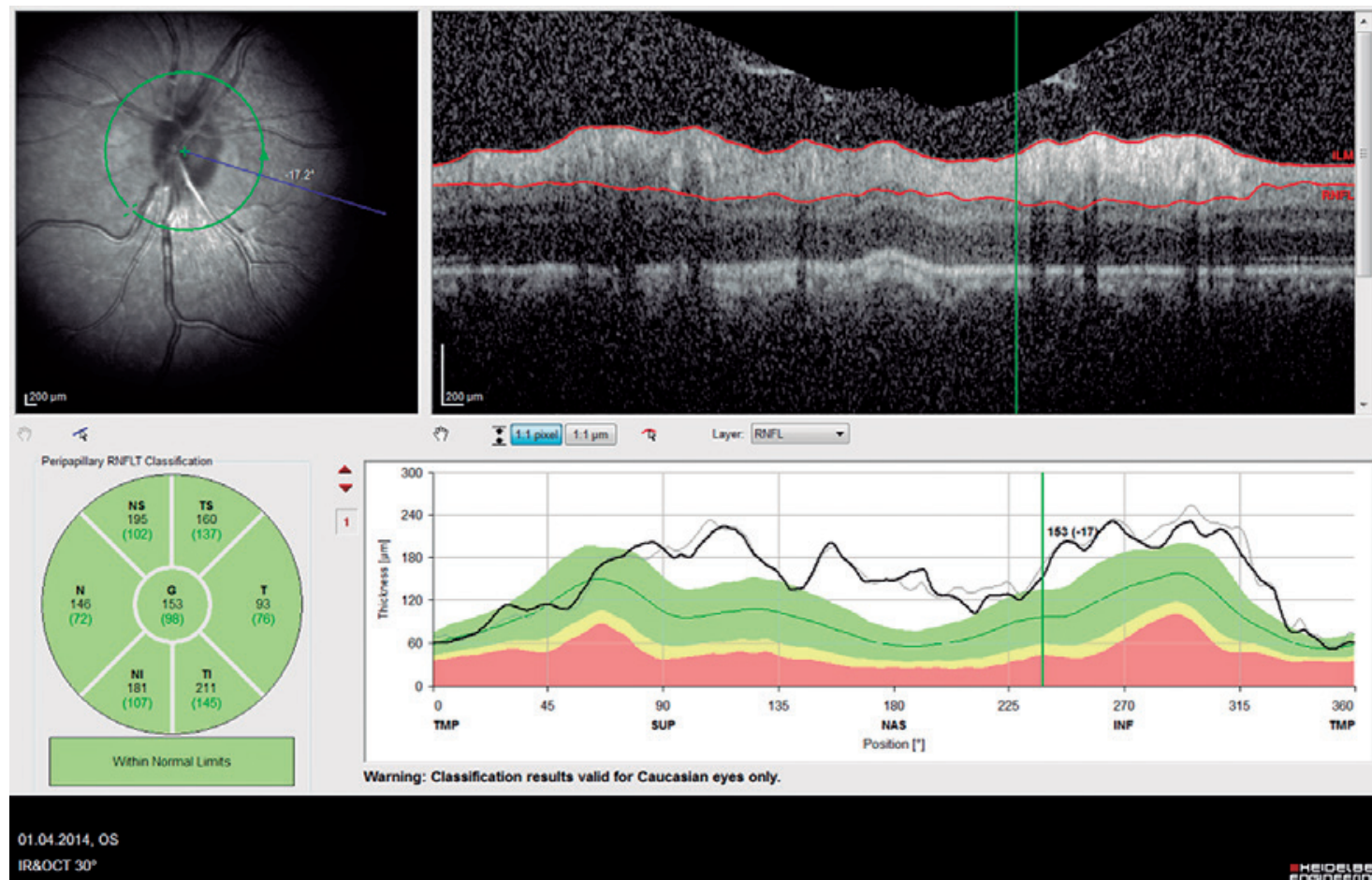

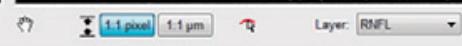

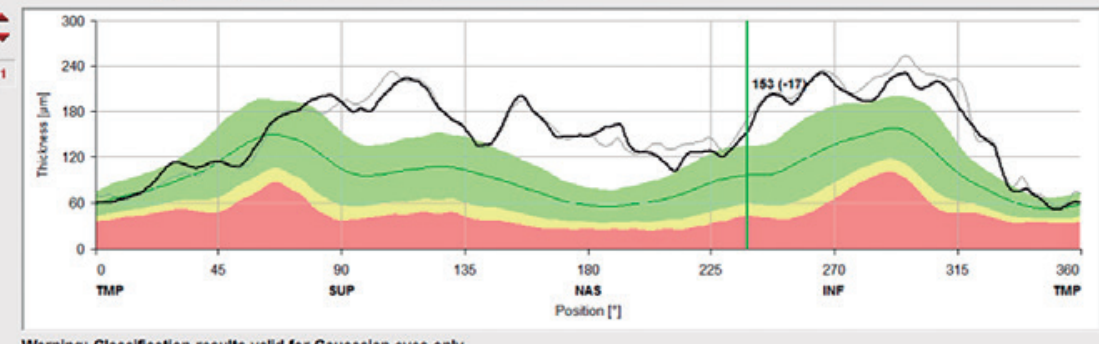

Warning: Classification results valid for Caucasian eyes only.

Figure 2. Example of retinal nerve fiber layer (RNFL) thicknesses classification.

Table 1. Demographic and clinical data according to the frequency of apnea-hypopnea per hour of sleep (apnea-hypopnea indexes, $\mathrm{AHI}$ ). Control group (C; $\mathrm{AHI}<5)$, mild obstructive sleep apnea syndrome (OSAS) group (M; $5 \leq \mathrm{AHI}<15)$, moderate OSAS group (Mo; $15 \leq \hat{A H I}<30$ ), and severe OSAS group (S; AlH $\geq 30)^{(16)}$

\begin{tabular}{|c|c|c|c|c|c|}
\hline & Group $C(n=18)$ & Group $M(n=19)$ & Group Mo $(n=16)$ & Group $S(n=19)$ & $P$ value \\
\hline Age & $47.6 \pm 6.6$ & $50.3 \pm 7.5$ & $45.00 \pm 10.3$ & $53.0 \pm 5.4$ & $0.053^{b}$ \\
\hline Sex & $9 \mathrm{M} / 9 \mathrm{~F}$ & $9 \mathrm{M} / 10 \mathrm{~F}$ & $8 \mathrm{M} / 8 \mathrm{~F}$ & $9 \mathrm{M} / 10 \mathrm{~F}$ & $>0.050$ \\
\hline SE & $-0.40 \pm 0.45$ & $0.18 \pm 0.89$ & $-0.39 \pm 0.86$ & $-0.01 \pm 0.95$ & $0.085^{c}$ \\
\hline IOP & $15.10 \pm 2.70$ & $13.90 \pm 2.70$ & $13.40 \pm 2.20$ & $15.00 \pm 2.60$ & $0.145^{c}$ \\
\hline$A L$ & $23.80 \pm 0.80$ & $23.20 \pm 0.90$ & $23.70 \pm 0.60$ & $23.60 \pm 0.80$ & $0.163^{b}$ \\
\hline $\mathrm{AHI}$ & 0.0 & 9.40 & 21.70 & 45.10 & $<0.050^{c}$ \\
\hline BMI & $26.6 \pm 2.8$ & $27.7 \pm 2.5$ & $27.5 \pm 2.9$ & $32.7 \pm 2.1$ & $<0.050^{b}$ \\
\hline
\end{tabular}

Variables are expressed as the mean \pm standard deviation.

$\mathrm{M}=$ male; $\mathrm{F}=$ female $\mathrm{SE}=$ spherical equivalent; diopter; $\mathrm{IOP}=$ intraocular pressure; $\mathrm{mmHg} ; \mathrm{Al}=$ axial length; $\mathrm{mm} ; \mathrm{AHI}=$ apnea-hypopnea index; $\mathrm{BMI}=$ body mass index; $\mathrm{kg} / \mathrm{m}^{2}$.

${ }^{a}=$ level of significance, $P<0.05 ;{ }^{b}=$ one-way ANOVA; ${ }^{c}=$ Kruskal-Wallis test 
Measurements of posterior ocular structures of groups C, M, Mo, and $\mathrm{S}$ are given in detail in table 2. No significant differences were observed among the groups in terms of CMT, CSCT, TCT, NCT, and RNFLs measurements $(p=0.184, p=0.056, p=0.230, p=0.320, p>0.005$, respectively).

After treatment, some posterior ocular structures changed significantly in group S. While the CMT was $273.05 \mu \mathrm{m}$ before treatment, it decreased to $272.00 \mu \mathrm{m}$ after 4 weeks and to $270.52 \mu \mathrm{m}$ after 12 weeks. Furthermore, the CSCT was $290.47 \mu \mathrm{m}$ before treatment and decreased to $285.68 \mu \mathrm{m}$ after 4 weeks and to $277.42 \mu \mathrm{m}$ after 12 weeks. Finally, the mean RNFL was $101.10 \mu \mathrm{m}$ before treatment, which decreased to $99.26 \mu \mathrm{m}$ after 4 weeks and to $96.47 \mu \mathrm{m}$ after 12 weeks. Table 3 shows these data in detail. Whereas statistically significant thinning was observed in the CSCT, G, Ni, Ns, and Ts during the 3-month follow-up of individuals with severe OSAS $(p=0.005$, $p=0.009, p=0.039, p=0.003$, and $p=0.02$, respectively), no statistically significant changes were found in the CMT, NCT, TCT, T, Ti, or N measurements.

\section{DISCUSSION}

Various pathologies can be triggered by the additional effects that hemodynamic, humoral, and neurological changes have on circulation because of the resultant hypoxic and hyperbaric attacks that develop during OSAS. For instance, the frequency of macular edema is higher in individuals with OSAS with diabetes mellitus (DM) than in normal individuals, and thus OSAS poses a different risk for those with DM in terms of macular edema ${ }^{(18)}$. Additionally, ocular diseases such as glaucoma usually accompany OSAS(10,19).

The effects of OSAS on posterior ocular tissues have been investigated in several studies ${ }^{(11-14)}$. In a study which investigated the differences in choroidal and RNFL thickness, the control group was

Table 2. Posterior ocular structures measurements according to the frequency of apnea-hypopnea per hour of sleep (apnea-hypopnea indexes, AHI). Control group (C; $\mathrm{AHI}<5)$, mild obstructive sleep apnea syndrome (OSAS) group $(\mathrm{M} ; 5 \leq \mathrm{AHI}<15)$, moderate OSAS group (Mo; $15 \leq \mathrm{AHI}<30)$, and severe OSAS group $(\mathrm{S} ; \mathrm{AlH} \geq 30)^{(16)}$

\begin{tabular}{lccccc}
\hline & Group C (n=18) & Group M (n=19) & Group Mo (n=16) & Group S (n=19) & $\boldsymbol{p ~ v a l u e ~}^{\mathrm{a}}$ \\
\hline Choroidal thicknesses & & & & & \\
CSCT & $302.50 \pm 86.90$ & $323.60 \pm 67.60$ & $322.90 \pm 76.80$ & $290.47 \pm 69.20$ & $0.056^{b}$ \\
NCT & $278.50 \pm 81.45$ & $278.05 \pm 92.28$ & $284.20 \pm 82.20$ & $234.26 \pm 57.33$ & $0.320^{c}$ \\
TCT & $288.27 \pm 80.79$ & $284.73 \pm 85.99$ & $293.50 \pm 65.20$ & $242.47 \pm 56.78$ & $0.230^{c}$ \\
CMT & $272.11 \pm 17.43$ & $262.15 \pm 30.90$ & $259.56 \pm 19.97$ & $273.05 \pm 17.94$ & $0.184^{b}$ \\
Retinal fiber layer thicknesses & & & & & $0.847^{c}$ \\
N & $76.44 \pm 0.51$ & $76.78 \pm 14.10$ & $73.75 \pm 11.45$ & $74.42 \pm 15.62$ & $0.791^{c}$ \\
Ns & $113.00 \pm 1.81$ & $117.10 \pm 27.45$ & $112.18 \pm 17.77$ & $117.05 \pm 17.18$ & $0.452^{c}$ \\
Ni & $110.77 \pm 3.31$ & $113.42 \pm 25.52$ & $101.68 \pm 12.40$ & $109.36 \pm 32.16$ & $0.142^{c}$ \\
T & $71.00 \pm 2.42$ & $73.47 \pm 17.22$ & $69.93 \pm 7.55$ & $78.05 \pm 11.12$ & $0.480^{c}$ \\
TS & $130.44 \pm 2.95$ & $136.21 \pm 24.93$ & $134.00 \pm 10.25$ & $146.47 \pm 21.87$ & $0.705^{c}$ \\
Ti & $136.44 \pm 3.61$ & $136.89 \pm 20.09$ & $140.50 \pm 12.69$ & $132.26 \pm 32.65$ & $0.605^{c}$ \\
G & $97.55 \pm 9.27$ & $100.57 \pm 11.74$ & $97.37 \pm 5.94$ & $101.10 \pm 3.01$ & \\
\hline
\end{tabular}

Variables are expressed as the mean \pm standard deviation.

$\mathrm{CSCT}=$ central subfoveal choroidal thickness; $\mathrm{NCT}=$ nasal choroidal thickness; $\mathrm{TCT}=$ temporal choroidal thickness; $\mathrm{CMT}=$ central macular thickness; $\mathrm{N}=$ nasal; $\mathrm{Ns}=$ nasal superior; $\mathrm{Ni}=$ nasal inferior; $\mathrm{T}=$ temporal; $\mathrm{Ts}=$ temporal superior; $\mathrm{Ti}=$ temporal inferior; $\mathrm{G}=$ mean .

a $=$ level of significance, $P<0.05 ;{ }^{b}=$ one-way ANOVA; ${ }^{c}=$ Kruskal-Wallis test.

Table 3. Changes in the thicknesses of posterior ocular structures in severe obstructive sleep apnea syndrome (OSAS) over time

\begin{tabular}{|c|c|c|c|c|}
\hline & BT $(n=19)$ & A4W $(n=19)$ & A12W $(n=19)$ & $p$ value ${ }^{a}$ \\
\hline $\mathrm{CSCT}$ & 290.47 & 285.68 & 277.42 & $0.005^{b}$ \\
\hline $\mathrm{NCT}$ & 234.26 & 237.15 & 233.10 & $0.240^{b}$ \\
\hline TCT & 242.47 & 248.47 & 236.57 & $0.410^{b}$ \\
\hline CMT & 273.05 & 272.00 & 270.52 & $0.330^{\mathrm{b}}$ \\
\hline G & 101.10 & 99.26 & 96.47 & $0.009^{b}$ \\
\hline Ts & 146.47 & 138.10 & 137.05 & $0.020^{b}$ \\
\hline T & 78.05 & 77.73 & 75.26 & $0.232^{b}$ \\
\hline Ti & 132.26 & 132.21 & 132.94 & $0.991^{b}$ \\
\hline N & 74.42 & 74.89 & 72.36 & $0.631^{b}$ \\
\hline $\mathrm{Ni}$ & 109.36 & 105.68 & 103.57 & $0.039^{b}$ \\
\hline Ns & 117.05 & 115.94 & 111.78 & $0.003^{b}$ \\
\hline
\end{tabular}

BT= before treatment: $\mathrm{A} 4 \mathrm{~W}=$ after 4 weeks; $\mathrm{A} 12 \mathrm{~W}=$ after 12 weeks; $\mathrm{CSCT}=$ central subfoveal choroidal thickness; $\mathrm{NCT}=$ nasal choroidal thickness: $\mathrm{TCT}=$ tempora choroidal thickness; $C M T=$ central macular thickness; $\mathrm{G}=$ mean peripapillary RNFL thickness; $\mathrm{Ts}=$ temporal superior; $\mathrm{T}=$ temporal; $\mathrm{Ti}=$ temporal inferior; $\mathrm{N}=$ nasal; $\mathrm{Ni}=$ nasal inferior; $\mathrm{Ns}=$ nasal superior.

a $=$ level of significance, $P<0.05 ;{ }^{b}=$ repeated measures ANOVA. 
compared with mild, moderate, and severe OSAS groups ${ }^{(12)}$. In the severe group, the nasal choroid was found to be thinner than that in the moderate OSAS group and thicker than that in the control group. In our study, although differences in thickness were observed, no significant differences were found between the control group and the other OSAS groups in terms of CMT, CSCT, NCT, TCT, and RNFL thickness. As mentioned above, OSAS causes substantial changes in the vascular system. Although they do not cause apparent clinical findings, such as glaucoma, hypertension i.e. injury induced by these changes can manifest systemically in the vascular system. However, the duration for which it influences the vascular system depends on the duration of the disease and the presence of other factors that can cause additional vascular injury. In a study that was conducted on the response of the choroid to hypocapnia in patients with OSAS, it was demonstrated that choroidal reflexes in individuals in which cardiovascular system CVS is not affected do not differ from that in normal individuals ${ }^{(20)}$. Patients in our study were individuals who were newly diagnosed with OSAS without a systemic component, which could have caused the lack of differences in the initial measurements. Thus, although patients in the severe OSAS group received treatment, significant thinning was observed in the CSCT and RNFL quadrants in this group as in the aforementioned study ${ }^{(12)}$. In contrast, when the CMT was evaluated in our study, no significant change was observed either in the initial measurements or during follow-up.

In another study in which changes in choroidal and macular thicknesses in OSAS were investigated, choroidal thinning was observed during the course of the disease ${ }^{(13)}$. Similarly, in our study, changes in nasal, temporal, and central choroidal thickness were measured but no significant changes were found ${ }^{(13)}$. Similar to our study, the previous study also investigated macular thickness, and it was determined that the central and nasal macular regions were thicker in the severe OSAS group than in the control group. The author compared the decreased choroid thickness and increased macular thickness to findings in diabetic retinopathy, and noted that macular thickening can result from vascular damage and increased permeability. In our study, at first glance, the existence of no difference between the groups can be interpreted as there was no effect on vascular structures and that damage occurred. But, vascular damage and the appearance of the effects of this damage are determined by different elapsed times and personal variations of tissue reaction. In any case, a change in macular thickness was observed and choroidal thinning took place during the follow-ups.

In a previous study on OSAS in which the choroidal thickness was evaluated, choroidal thinning was observed in patients with severe OSAS ${ }^{(14)}$. The author emphasized that this finding could have been caused by impaired blood and auto regulations in OSAS. The results of the patients with OSAS in that study were similar to those of the severe OSAS group in our study; the mean AHI in the previous study was 48 , whereas the mean AHI in the severe OSAS group in our study was 45.1. Our study indicates that although the measurements of those with severe OSAS are not normal and do not differ from those of patients with less severe forms of OSAS' others with OSAS, eventual thinning of the choroidal thickness and RNFL sectors shows that the disease has progressive effects both in blood regulation and RNFL injury.

Similar to our study, thinning of the RNFL was also found in a previous study on patients with OSAS who were followed up for 3 months ${ }^{(21)}$. Followed up patients received treatment with CPAP in that study. Whereas only those with $\mathrm{AHI} \geq 30$ received treatment in our study, treatment was administered to those with $\mathrm{AHI} \geq 5$ in the previous study. Data from our study are similar to those from the previous study: whereas thinning in the RNFL and the Ts, Ns, and Ni quadrants was observed, changes in the other quadrants were not statistically significant. The author stated that the tendency of individuals with OSAS to develop glaucoma could have had an effect on that result. Although ganglion cell injury is generalized in glaucoma, the inferior and superior quadrants can be affected earlier in the disease progression ${ }^{(22)}$. Furthermore, while the mean IOP statistically significantly increased in our study, it did not reach the normal range. Thinning in the RNFL can occur not only because of glaucoma but also because of apnea-hypopnea, nocturnal hypotension, and impairment of the balance between $\mathrm{NO}$ and endothelin, leading to hypoperfusion and ischemia. Compared with most of the studies in this field, a statistically insignificant difference in RNFL thickness was found between the control group and patients with OSAS in our study.

In a study on the relationship of RNFL and other vascular pathologies with OSAS, an inverse relationship was found between $\mathrm{AHI}$ and RNFL thickness ${ }^{(15)}$. Additionally, an inverse relationship was found between atherosclerosis and nasal RNFL thickness. It has been demonstrated that in young, healthy individuals, temporal retinal regions are more vascularized than nasal regions ${ }^{(23,24)}$. This can explain why nasal tissues are damaged much earlier in hypoxia. Thus, in the majority of other studies and in ours, the nasal RNFL quadrants were affected. In the aforementioned study, inverse relationships were established between nasal RNFL thickness and atherosclerosis, BMI, and highdensity lipoprotein cholesterol levels ${ }^{(15)}$. Moreover, in another study that investigated the retina and optic nerve in adult OSAS patients using OCT, the nasal part of the RNFL was found to be thinner in OSAS patients than in the control group (without relevance to the classification of OSAS)(25). The aforementioned reasons such as hypoxia, hypercapnia i.e. are factors that somehow decrease the vascular supply, and the effect on the nasal quadrants occurred much earlier, thus confirms the results of our study. Our findings of statistically insignificant differences between the groups in terms of the initial RNFL thickness may be attributable to the exclusion of patients with glaucoma from our study, as glaucoma is more common in OSAS populations than in normal populations ${ }^{(10,20)}$.

There are several limitations to our study that should be acknowledged. First, we included a relatively small number of patients in our study. Second, as systemic illnesses and eye diseases such as glaucoma are common in patients with OSAS, the inclusion of patients without any ocular or systemic diseases other than OSAS in our study is another limitation. The exclusion of people with glaucoma from our study may also explain the similar initial RNFL thicknesses found in the study groups.

In our study, we compared untreated patients with OSAS who were newly diagnosed and had no systemic disease. Individuals with severe OSAS who received CPAP treatment were re-evaluated after 4 and 12 weeks in terms of posterior ocular changes. In the first measurement no statistical difference was found between control group and the OSAS' the normal group and other groups. Despite the fact that the individuals with severe OSAS who were followed up, benefitted from treatment clinically; statistically significant thinning in the CSCT, general RNFL, Ts, Ni, and Ns quadrants was found. Although patients with severe OSAS may recover clinically, we recommend that they be followed up in terms of ocular ischemic injury.

\section{ACKNOWLEDGMENTS}

The authors thank all the staff of the Ophthalmology Department - in particular, Sevilay Sözeri - for their contributions to the follow-up of data in our study and communication with participants.

\section{REFERENCES}

1. Punjabi NM. The epidemiology of adult obstructive sleep apnea. Proc Am Thorac Soc. 2008;5(2):136-43.

2. Waller EA, Bendel RE, Kaplan J. Sleep disorders and the eye. Mayo Clin Proc. 2008; 83(11):1251-61

3. Caples SM, Garcia-Touchard A, Somers VK. Sleep-disordered breathing and cardiovascular risk. Sleep. 2007:30(3):291-303.

4. Levy P, Pepin JL, Arnaud C, Baguet JP, Dematteis M, Mach F. Obstructive sleep apnea and atherosclerosis. Prog Cardiovasc Dis. 2009;51(5):400-10 
5. Arnaud C, Dematteis M, Pepin JL, Baguet JP, Levy P. Obstructive sleep apnea, immunoinflammation, and atherosclerosis. Semin Immunopathol. 2009;31(1):113-25.

6. Waradekar NV, Sinoway LI, Zwillich CW, Leuenberger UA. Influence of treatment on muscle sympathetic nerve activity in sleep apnea. Am J Respir Crit Care Med. 1996; 153(4 Pt 1)1333-8.

7. Nickla DL, Wallman J. The multifunctional choroid. Prog Retin Eye Res. 2010;29(2):144-68.

8. Mojon DS, Mathis J, Zulauf M, Koerner F, Hess CW. Optic neuropathy associated with sleep apnea syndrome. Ophthalmology. 1998;105(5):874-7.

9. Fuchsiager-Mayrl G, Luksch A, Malec M, Polska E, Wolzt M. Schmettener K. Role of endothelin-1 in choroidal blood flow regulation during isometric exercise in healthy humans. Invest Ophthalmol Vis Sci. 2003;44(2):728-33.

10. Bendel RE, Kaplan J, Heckman M, Fredrickson PA, Lin SC. Prevalence of glaucoma in patients with obstructive sleep apnoea - a cross-sectional case series. Eye(Lond) 2008;22(9):1105-9.

11. Lin PW, Friedman $\mathrm{M}$, Lin HC, Chang HW, Pulver TM, Chin CH. Decreased retinal nerve fiber layer thickness in patients with obstructive sleep apnea/hypopnea syndrome. Graefes Arch Clin Exp Ophthalmol. 2011;249(4):585-93.

12. Bayhan HA, Aslan Bayhan S, Intepe YS, Muhafiz E, Gürdal C. Evaluation of the macular choroidal thickness using spectral-domain optical coherence tomography in patients with obstructive sleep apnoea syndrome: response. Clin Experiment Ophthalmol. 2015;43(2):139-44.

13. Xin C, Wang J, Zhang W, Wang L, Peng X. Retinal and choroidal thickness evaluation by SD-OCT in adults with obstructive sleep apnea-hypopnea syndrome (OSAS). Eye (Lond). 2014;28(4):415-21.

14. Karalezli A, Eroglu FC, Kivanc T, Dogan R. Evaluation of choroidal thickness using spectral-domain optical coherence tomography in patients with severe obstructive sleep apnea syndrome: a comparative study. Int J Ophthalmol. 2014;7(6):1030-4.

15. Shiba T, Takahashi M, Sato Y, Onoda Y, Hori Y, Sugiyama T et al. Relationship between severity of obstructive sleep apnea syndrome and retinal nerve fiber layer thickness. Am J Ophthalmol. 2014;157(6):1202-8.

16. Epstein LJ, Kristo D, Strollo PJ, Friedman N, Malhotra A, Patil SP, Ramark K, Rogers R,
Schwab RJ, Weaver EM, Weinstein MD; Adult Obstructive Sleep Apnea Task Force of the American Academy of Sleep Medicine. et al. Clinical guideline for the evaluation, management and long-term care of obstructive sleep apnea in adults. J Clin Sleep Med. 2009;15.5(3):263-76.

17. Spaide RF, Koizumi H, Pozonni MC, Enhanced depth imaging spectral-domain optical coherence tomography. Am J Ophthalmol. 2008;146(4):496-500. Erratum in: Am J Ophthalmol. 2009;148(2):325

18. Usui S, Ikuno Y, Akiba M, Maruko I, Sekiryu T, Nishida et al. Circadian changes in subfoveal choroidal thickness and the relationship with circulatory factors in healthy subjects. Invest Ophthalmol Vis Sci. 2012;53(4):2300-7.

19. Mason RH, West SD, Kiire CA, Groves DC, Lipinski HJ, Jaycock A, et al. High prevalence of sleep disordered breathing in patients with diabetic macular edema. Retina. 2012; 32(9):1791-8. Comment in: Retina. 2012;32(10):2180; author reply 2180.

20. Lin PW, Friedman M, Lin HC, Chang HW, Wilson M, Lin MC. Normal tension glaucoma in patients with obstructive sleep apnea/hypopnea syndrome. J Glaucoma. 2011; 20(9):553-8.

21. Khayi H, Pepin $J$, Geiser MH, Tonini M, Tamisier R, Renard E, et al. Choroidal blood flow regulation after posture change or isometric exercise in men with obstructive sleep apnea syndrome. Invest Ophthalmol Vis Sci. 2011;16;52(13):9489-96.

22. Zengin MO, Tuncer I, Karahan E. Retinal nerve fiber layer thickness changes in obstructive sleep apnea syndrome: one year follow-up results. Int J Ophthalmol. 2014; 7(4):704-8.

23. Leung CK, Lam S, Weinreb RN, Liu S, Ye C, Liu L, et al. Retinal nerve fiber layer imaging with spectral-domain optical coherence tomography: analysis of the retinal nerve fiber layer map for glaucoma detection. Ophtalmology. 2010;117(9):1684-91.

24. Garhofer G, Werkmeister R, Dragostinoff N, Schmetterer L. Retinal blood flow in healthy young subjects. Invest Ophthalmol Vis Sci. 2012;53(2):698-703.

25. Casas P, Ascaso FJ, Vicente E, Tejero-Garcés G, Adiego Ml, Cristóbal JA. Retinal and optic nerve evaluation by optical coherence tomography in adults with obstructive sleep apnea-hypopnea syndrome (OSAHS). Graefes Arch Clin Exp Ophthalmol. 2013:251(6):1625-34 